\title{
Prevention of early-onset familial/hereditary colon cancer: New models and mechanistic biomarkers (Review)
}

\author{
NITIN T. TELANG, GUO LI and MEENA KATDARE \\ Carcinogenesis and Chemoprevention, Research Laboratory, Strang Cancer Prevention Center \\ and Department of Surgery, Weill Medical College, New York, NY, USA
}

Received December 19, 2005; Accepted February 6, 2006

\begin{abstract}
Human colon cancer is a multi-factorial, multi-step disease wherein genetic and dietary factors represent important regulators of initiation, promotion and progression. While the etiology of sporadic colon cancer remains largely unidentified, familial adenomatous polyposis (FAP) and hereditary non-polyposis colon cancer (HNPCC) represent predisposing genetic syndromes for early-onset familial/hereditary colon cancer. These syndromes are characterized by germ-line mutations in the adenomatous polyposis coli (APC) and/or DNA mismatch repair genes, respectively. Currently available preclinical animal models for human FAP and HNPCC syndromes, expressing clinically relevant germ-line mutations, exhibit adenomas in the small intestine rather than in the colorectum. These models are, therefore, subject to extrapolation for direct clinical translatability of the data for colon carcinogenesis and chemoprevention. Experimental models expressing clinically relevant genetic defects (APC and/or DNA mismatch repair gene mutations) in an appropriate target site (colon) may represent novel approaches that reduce extrapolation of the data for their clinical relevance. This report provides an overview on carcinogenesis and chemoprevention in preclinical models of FAP and HNPCC syndromes, and summarizes recent data on i) development of new cell culture models for FAP and HNPCC syndromes; and ii) validation of developed models for rapid, mechanism-based screening of new pharmacological or naturally occurring chemopreventive agents.
\end{abstract}

\section{Contents}

1. Introduction

2. Model systems and mechanistic biomarkers

Correspondence to: Dr Nitin T. Telang, Strang Cancer Research Laboratory, The Rockefeller University, 1230 York Avenue, New York, NY 10021, USA

E-mail: telangn@mail.rockefeller.edu msk2004@med.cornell.edu

Key words: colon epithelial cell culture, FAP/HNPCC syndromes, prevention
3. Modulation of carcinogenesis

4. Conclusions and future perspectives

\section{Introduction}

A survey by the American Cancer Society projected a $23 \%$ incidence $(148,300$ new cases) and $21 \%$ mortality $(56,600$ colon cancer related deaths) rate in 2005 (1). These figures represent the overall risk for sporadic, familial and hereditary colon cancer, partly based on common molecular/genetic pathways predisposing the disease.

Several elegant seminal observations have provided support to the concept that, in the multi-step process of colon carcinogenesis, early occurring molecular/genetic events (such as germ-line or somatic mutations in APC, k-ras and/or p53 genes) initiate the normal target tissue towards preneoplastic and neoplastic transformation. The initiated phenotype is then at risk for subsequent promotion and progression predominantly due to aberrant hyperproliferation, downregulated apoptosis and abrogation of dependency on extrinsic growth regulatory factors (2-5).

In progressive pathogenesis, intraepithelial neoplasia (IEN) have been considered as relevant pre-cancerous lesions for epithelial organ site carcinomas (6). The pathogenesis of colon cancer is characterized by the presence of polypoid or nonpolypoid adenomas in FAP and HNPCC syndromes. At the molecular levels, these lesions recapitulate defects in tumor suppressor genes and DNA mismatch repair genes $(3,4)$. These IEN, because of their molecular/genetic and pre-neoplastic characteristics, represent an important end-point for efficacy of chemopreventive interventions.

Chemoprevention of epithelial organ site carcinogenesis, using synthetic pharmacological agents or naturally occurring dietary phytochemicals to inhibit, reduce or delay the multistep carcinogenic process has attracted intense scientific interest in recent years. The ability of chemopreventive agents at low, non-toxic levels to target early occurring carcinogenic events represents a major promising aspect for clinical preventive intervention $(6,7)$.

Preclinical models developed from mice expressing mutations in the tumor suppressor, APC, or DNA-mismatch repair genes and demonstrating a quantifiable risk for intestinal carcinogenesis provide valuable approaches to identify molecular/genetic determinants for the risk of early-onset 
Table I. Characterization of the FAP and HNPCC models.

\begin{tabular}{lcccccc}
\hline & \multicolumn{2}{c}{ Genotype } & & & \multicolumn{2}{c}{$\begin{array}{c}\text { Transformation } \\
\text { AICF }\end{array}$} \\
\cline { 2 - 3 } Cell line & APC & Mlh1 & & Model & Immortalization & - \\
\cline { 6 - 7 } C57COL & $+/+$ & $+/+$ & Control & + & + \\
1638NCOL & $+/-$ & $+/+$ & FAP & + & - \\
Mlh1COL & $+/+$ & $+/-$ & HNPCC & + & + \\
Mlh1/1638NCOL & $+/-$ & $+/-$ & HNPCC & + & + \\
\hline
\end{tabular}

familial/hereditary colon cancer and its prevention (2-4). However, these models, unlike the human FAP and HNPCC syndromes, exhibit adenomas predominantly in the small intestine, rather than in the colorectum (8-11). Alternative approaches that result in defined target site specificity may minimize the need for extrapolation and maximize a clinically relevant translational potential. In this context, it is noteworthy that pharmacological or genetic modulation in APC mutant mice has resulted in enhanced incidence of colonic adenomas and adenocarcinoma (12-16).

The long-term objective of our research program has been to develop reliable cell culture models for breast and colon carcinogenesis and validate the developed models for rapid mechanism-based screening of new chemopreventive agents. To this end, several immortalized but non-tumorigenic epithelial cell lines from histologically/clinically normal target tissue have been developed. In these cell lines, exposure to chemical carcinogens or transfection with selected clinically relevant oncogenes results in aberrant cell cycle progression, down-regulation of apoptosis, altered expression of cell cycle regulatory and apoptosis associated gene products, and anchorage-independent growth in vitro preceding tumorigenesis in vivo (17-20). Additionally, the transformed cell lines respond to treatment with several mechanistically distinct chemopreventive agents, and exhibit effective modulation of the perturbed surrogate end-point biomarkers for carcinogenic risk (21-28). More recently, this technology has been extended to develop sub-culturable colon epithelial cell lines from gene knockout mouse models for FAP and HNPCC syndromes (Telang et al, Proc. Am Assoc Cancer Res 43: abs 1007, 2002; Katdare et al, Proc Am Assoc Cancer Res 43: abs. 624, 2002; 30,31,36).

The present review provides an in-depth discussion of the data on preclinical animal models of FAP and HNPCC syndromes, and summarizes recently completed studies on the newly developed cell culture models for early-onset familial/hereditary colon cancer.

\section{Model systems and mechanistic biomarkers}

In vivo models. Homologous recombination or random chemically induced mutagenesis has been used to generate a series of APC [+/-] mice that exhibit mutation in codons $474,716,850$ or 1638 of the APC tumor suppressor gene and encode a truncated gene product. Similar recombination approaches have also generated mouse models with mutations in the DNA mismatch repair genes. Mlh1 [+/-], Mlh1 [-/-],
Msh6 [+/-] and Msh6 [-/-] mice exhibit accelerated small intestinal carcinogenesis, which is further enhanced in APC [+/-]/DNA-MMR [+/-] mice (11). These genetic defects are similar to those observed in clinical HNPCC syndromes. These mutant mice are predisposed to develop small intestinal adenomas that frequently exhibit loss of the second APC allele (2,8-10). However, because of a distinct target site than that in clinical FAP and HNPCC syndromes (8-11), these models are subject to extrapolation for their clinical relevance and translatability.

Mechanistic biomarkers. The biomarkers traditionally utilized to monitor tumorigenesis in preclinical animal models include pathogenic markers such as adenoma incidence, latency and multiplicity, and molecular/genetic markers such as loss of heterozygosity, chromosomal aberration, microsatellite instability, APC signaling and DNA damage/repair. The modulations in these biomarkers also represent quantitative parameters to evaluate the preventive efficacy of several mechanistically distinct classes of pharmacological agents.

Cell culture models. Most of the available cell culture models are derived from established human colon carcinoma cell lines that have multiple pre-existing genetic defects such as monoallelic and/or biallelic mutations or $\mathrm{LOH}$ for APC, p53, Ras or DNA-MMR genes. These models, however, are of limited utility in studies focused on examining the role of clinically relevant genetic defects on early initiating events that have an impact upon the risk of carcinogenesis.

Our currently ongoing research directions have focused on developing subculturable colon epithelial cell lines from mice that exhibit genetic predisposition to intestinal carcinogenesis. We have utilized pathologically and histologically normal descending colon from mice that express monoallelic mutations in APC, Mlh1 or APC/Mlh1 genes associated with clinical FAP and HNPCC syndromes to establish the cell culture models.

The data presented in Table I, lists the cell lines developed from the mutant mice. The cell line, $\mathrm{C} 57 \mathrm{COL}$, developed from descending colon of wild-type APC [+/+]/DNA-MMR [+/+] C57BL/6J mouse represents the control cell line. These cell lines have been characterized for the onset of spontaneous immortalization by monitoring replicative senescence. Cells undergoing apoptosis and lack of subculture-ability evidenced the expression of this biomarker. It is noteworthy that C57COL exhibited replicative senescence and apoptosis during p10-p16. A minor subpopulation escaped replicative senescence and 
Table II. Aberrant hyperproliferation in FAP and HNPCC models.

\begin{tabular}{lcccc}
\hline Cell line & Model & $\begin{array}{c}\text { Population } \\
\text { doubling time (h) }\end{array}$ & $\begin{array}{c}\text { Saturation density } \\
\text { cell no. (x10 })\end{array}$ & $\begin{array}{c}\text { AICF (No. of } \\
\text { colonies) }\end{array}$ \\
\hline C57COL & Control & 34 & 7.7 & 0 \\
1638 NCOL & FAP & 17 & 27.0 & $16.7 \pm 1.6$ \\
1638 NCOL-CL ${ }_{1}{ }^{2}$ & FAP & 15 & 48.0 & $18.5 \pm 1.2$ \\
Mlh1/1638NCOL & HNPCC & 20 & 15.0 & $13.2 \pm 2.0$ \\
Mlh1/1638NCOL-CL ${ }^{a}$ & HNPCC & 17 & 21.0 & $15.2 \pm 1.4$ \\
\hline
\end{tabular}

${ }^{\mathrm{a}}$ Clonal derivatives from anchorage-independent colony.

Table III. Abrogated homeostatic growth control in FAP and HNPCC models.

\begin{tabular}{lccrr}
\hline Cell line & Model & $\begin{array}{c}\text { Proliferation }^{\mathrm{a}} \\
\left(\mathrm{P}=\% \mathrm{~S}+\mathrm{G}_{2} / \mathrm{M}\right)\end{array}$ & $\begin{array}{c}\text { Apoptosis }^{\mathrm{a}} \\
\left(\mathrm{A}=\% \text { Sub G }_{0}\right)\end{array}$ & $\begin{array}{c}\text { P:A } \\
\text { ratio }\end{array}$ \\
\hline C57COL & Control & $24.6 \pm 3.3^{\mathrm{b}}$ & $4.3 \pm 1.1^{\mathrm{d}}$ & $5.7 \pm 0.8$ \\
$1638 \mathrm{NCOL}-\mathrm{CL}_{1}$ & FAP & $41.9 \pm 2.9^{\mathrm{c}}$ & $1.4 \pm 0.9^{\mathrm{e}}$ & $29.9 \pm 1.2$ \\
Mlh1/1638NCOL-CL & HNPCC & $31.2 \pm 2.4^{\mathrm{c}}$ & $2.8 \pm 0.9^{\mathrm{e}}$ & $11.1 \pm 1.2$ \\
\hline
\end{tabular}

${ }^{\mathrm{a}}$ Flow cytometry of confluent culture (at least $10^{4}$ fluorescent events monitored). ${ }^{\mathrm{b}-\mathrm{e}}$ Mean $\pm \mathrm{SD} ; \mathrm{n}=6$ per cell line; ${ }^{\mathrm{b}-\mathrm{c}, \mathrm{d}-\mathrm{e}} \mathrm{P}=0.04$.

was capable of extended life span in vitro, indicating the onset of spontaneous immortalization. These immortalized cells at p24 also exhibited re-expression of telomerase, which was absent in early passage (p16) cells. In contrast, the APC [+/-], Mlh1 [+/-] and Mlh1 [+/-]/APC [+/-] cells lacked replicative senescence and were subculturable at least up to p25. Furthermore, only the mutant cells exhibited a risk for tumorigenic transformation, as evidenced by a high incidence of anchorage-independent colony formation (AICF) in $0.33 \%$ agar (soft agar) as suspension cultures.

The data presented in Table II, summarizes the growth characteristics of mutant cell lines. The quantitative end-points include population doubling time, saturation density and AICF. Relative to the C57COL cell line from the wild-type APC $[+/+]$ C57BL/6J mouse, the mutant cell lines exhibit a $41-56 \%$ decrease in population doubling time, and a 2-5-fold increase in saturation density. It is also of interest to note that the mutant cells exhibit a $20-75 \%$ increase in the aneuploid phenotype, while the C57COL cells are 100\% diploid (data not shown). Thus, the presence of pre-existing genetic defects, such as monoallelic mutation in APC or in the DNAmismatch repair Mlh1 gene, up-regulation of aneuploidy and hyperproliferation taken together suggest that the mutant cells may be at a greater risk for spontaneous carcinogenic transformation. In this context, it is noteworthy that a high incidence of aneuploid population is demonstrated in early passage embryonic fibroblasts from APC mutant mice $(37,38)$, and genes implicated in colon cancer exhibit altered expression in non-involved colonic mucosa adjacent to adenoma in APC mutant mice as well as in tissue samples from colon cancer patients (39).

AICF represents a sensitive and specific surrogate endpoint biomarker for the risk of carcinogenic transformation. Several studies have shown that spontaneously immortalized, but non-tumorigenic cell lines acquire AICF in vitro prior to tumorigenicity in vivo in response to treatment with chemical carcinogens or targeted expression of oncogenes $(17,18,20,23)$. Furthermore, carcinoma derived cell lines also exhibit upregulated AICF. The data presented in Table II also compares AICF in C57COL and mutant cell lines. It is clearly demonstrated that, relative to the $\mathrm{C} 57 \mathrm{COL}$ cell line, the parental 1638 NCOL cell line and it's clonal derivative, 1638NCOL$\mathrm{CL}_{1}$, exhibit a 17- and 18-fold increase in the frequency of anchorage-independent colonies, respectively. Similarly, parental cells and the clonal derivative of the Mlh1/ 1638 NCOL cell line exhibit a 13 - to 15 -fold increase in the frequency of anchorage-independent colonies. It is also interesting to note that, unlike post-immortalized C57COL cells, post-immortalized APC 1638NCOL, and Mlh1/ 1638NCOL cells exhibit AICF, while Mlh1COL cells do not. These data together suggest that mutations in APC alone and in APC+Mlh1 but not in Mlh1 alone may be critical for enhancing the risk for spontaneous carcinogenic transformation.

The data presented in Table III, analyses the cell cycle progression. Relative to that in C57COL cells, aberrantly proliferative clonal derivatives of $1638 \mathrm{NCOL}$ and Mlh1/ $1638 \mathrm{NCOL}$ cells exhibit an increase in the $\mathrm{S}+\mathrm{G}_{2} / \mathrm{M}$ phase of the 
A. Saturation Density (Cell Number)

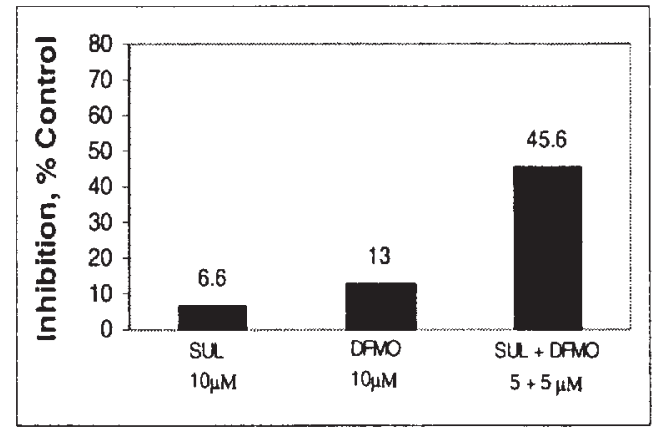

Cell Number in Control: $53.5 \pm 2.5 \times 10^{5}$

\section{B. Anchorage-independent Colony Formation}

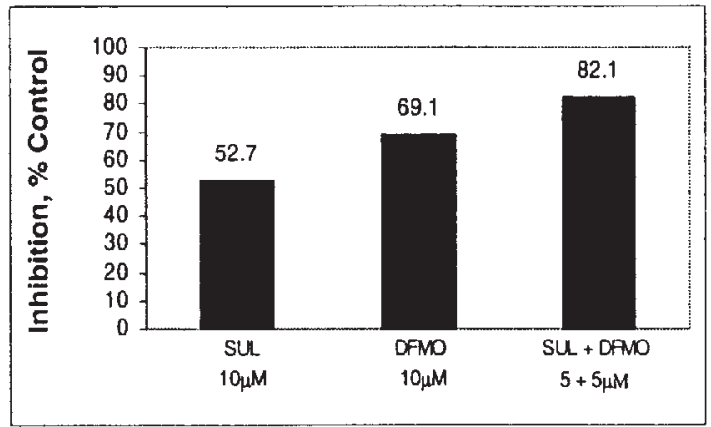

Colony Number in Control: $17.7 \pm 1.1$

Figure 1. Treatment of $1638 \mathrm{NCOL}-\mathrm{CL}_{1}$ cells with a combination of SUL+DFMO. A, percent decrease in viable cell number by treatment with SUL (10 $\mu \mathrm{M}$ ), DFMO $(10 \mu \mathrm{M})$ or SUL+DFMO $(5+5 \mu \mathrm{M})$. Viable cell number in solvent control: mean $\pm \mathrm{SD}, \mathrm{n}=6$ at day 5 post-seeding. B, percent decrease in the number of anchorage-independent colonies by treatment with SUL, DFMO or SUL+DFMO. Number of colonies in solvent controls: mean \pm SD, $n=12$ at day 14 postseeding.

\section{A. Saturation Density (Cell Number)}

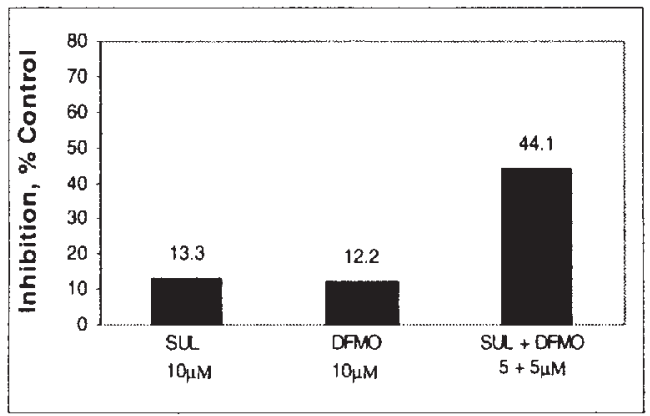

Cell Number in Control: $27.0 \pm 2.8 \times 10^{5}$

\section{B. Anchorage-independent Colony Formation}

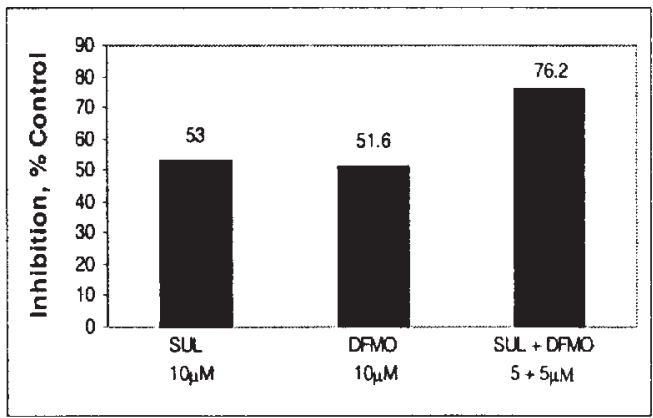

Colony Number in Control: $14.2 \pm 1.7$

Figure 2. Treatment of Mlh1/1638NCOL-CL 1 cells with a combination of SUL+DFMO. A, percent decrease in viable cell number by treatment with SUL (10 $\mu$ M), DFMO $(10 \mu \mathrm{M})$ or SUL+DFMO $(5+5 \mu \mathrm{M})$. Viable cell number in solvent controls: mean $\pm \mathrm{SD}, \mathrm{n}=6$ at day 5 post-seeding. B, percent decrease in the number of anchorage-independent colonies by treatment with SUL, DFMO or SUL+DFMO. Number of colonies in solvent controls: mean \pm SD, $n=12$ at day 14 postseeding.

cell cycle and a decrease in the sub- $\mathrm{G}_{0}$ (apoptotic) population; thereby, increasing the $\mathrm{P}: \mathrm{A}$ ratio.

Thus, the newly developed epithelial cell lines, because of clinically relevant genetic defect (APC and/or DNA-MMR mutation) at the appropriate target site (colon), and a quantifiable risk for carcinogenic transformation, represent valuable preclinical cell culture models for familial/hereditary early-onset FAP and HNPCC colon cancer syndromes.

Cellular and molecular targets for carcinogenic risk and chemo-preventive efficacy. In the multi-step carcinogenic process early occurring gain of function mutagenic perturbations in oncogenes or loss of function mutagenic perturbations in tumor suppressor genes induce aberrant hyperproliferation in the target cell, thereby increasing the risk for subsequent carcinogenic transformation. Thus, overexpression of HER-2/neu oncogene and loss of function mutations in BRCA-1 and BRCA-2 tumor suppressor genes are noted as genetic risk factors for breast cancer $(6,40,41)$, while activating mutation in Ras oncogene and loss of function mutations in APC and p53 tumor suppressor genes represent genetic risk factors for colon cancer (3). Specific and sensitive molecular, biochemical and cellular biomarker assays that quantify cell proliferation, cell cycle progression, cellular apoptosis and oncogene/tumor suppressor gene regulated signaling pathways represent mechanistic end-points for carcinogenesis as well as for cancer prevention. Our previous studies on mammary and colon cell culture models have demonstrated that, independent of the nature of carcinogenic insult, the target cells exhibit perturbed expression of relevant biomarkers in vitro preceding tumorigenesis in vivo (17-20,23,30,31,33). Furthermore, initiated target cells in response to mechanistically distinct chemopreventive agents exhibit down-regulation of perturbed end-point biomarkers (21-28,30,31,33-36).

\section{Modulation of carcinogenesis}

Pharmacological agents. The APC ${ }^{\text {Min }}$ mouse, because of a germ-line mutation in the APC tumor suppression gene, 
A. Saturation Density (Cell Number)

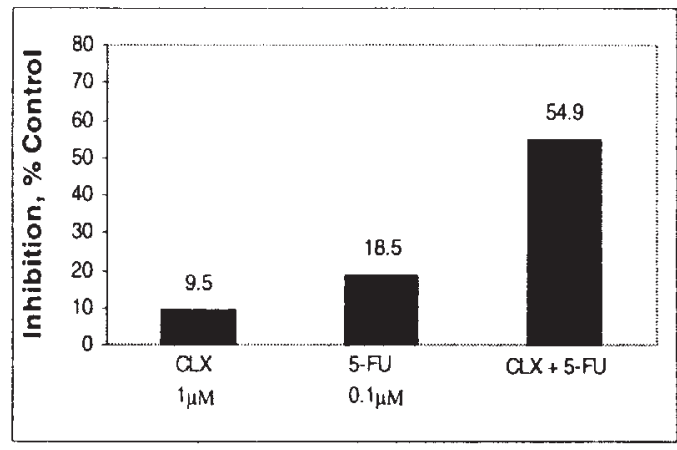

Cell Number in Control: $53.5 \pm 2.5 \times 10^{5}$
B. Anchorage-independent Colony Formation

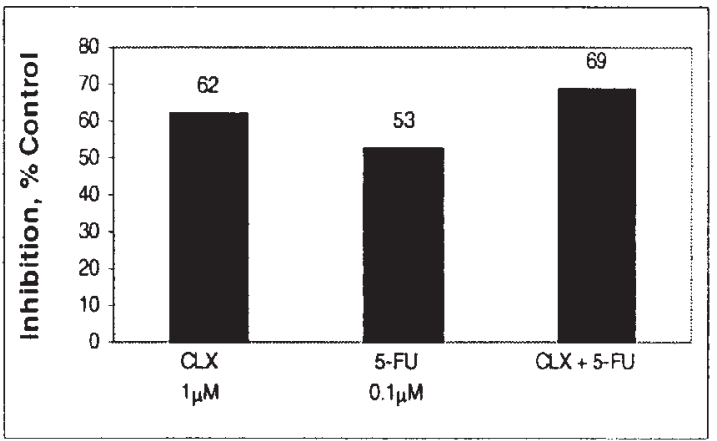

Colony Number in Control: $15.4 \pm 3.2$

Figure 3. Treatment of $1638 \mathrm{NCOL}-\mathrm{CL}_{1}$ cells with a combination of CLX+ 5-FU. A, percent decrease in viable cell number by treatment with CLX (1 $\left.\mu \mathrm{M}\right)$, 5-FU $(0.1 \mu \mathrm{M})$ or $\mathrm{CLX}+5-\mathrm{FU}(1+0.1 \mu \mathrm{M})$. Viable cell number in solvent controls: mean $\pm \mathrm{SD}, \mathrm{n}=6$ at day 5 post-seeding. B, percent decrease in the number of anchorage-independent colonies by treatment with CLX, 5-FU or CLX+5-FU. Number of colonies in solvent controls: mean \pm SD, $\mathrm{n}=12$ at day 14 postseeding.

A. Saturation Density (Cell Number)

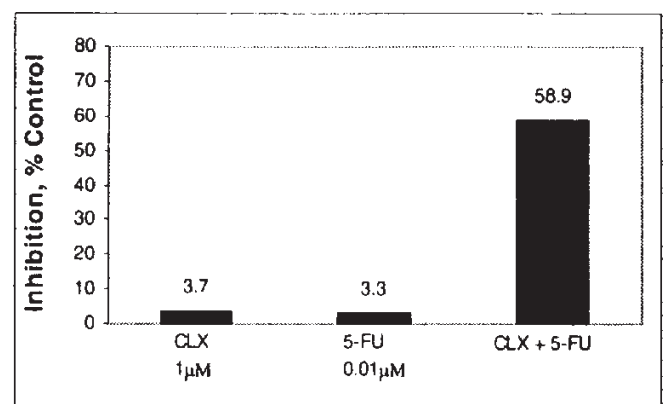

Cell Number in Control: $28.9 \pm 3.3 \times 10^{5}$

\section{B. Anchorage-Independent Colony Formation}

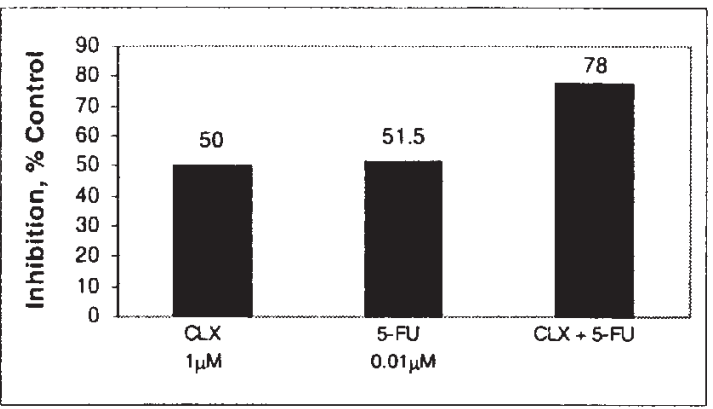

Colony Number in Control: $13.2 \pm 2.0$

Figure 4. Treatment of Mlh1/1638NCOL-CL ${ }_{1}$ cells with a combination of CLX+5-FU. A, percent decrease in viable cell number by treatment with CLX $(1 \mu \mathrm{M}), 5-\mathrm{FU}(0.01 \mu \mathrm{M})$ or CLX+5-FU $(1+0.01 \mu \mathrm{M})$. Viable cell number in solvent control: mean $\pm \mathrm{SD}, \mathrm{n}=6$ at day 5 post-seeding. B, percent decrease in the number of anchorage-independent colonies by treatment with CLX, 5-FU or CLX+5-FU. Number of colonies in the solvent controls: mean \pm SD, $\mathrm{n}=12$ at day 14 post-seeding.

exhibits a high incidence of intestinal adenomas resembling clinical early-onset FAP syndrome $(9,10)$. In recent years, the $\mathrm{APC}^{\mathrm{Min}}$ model has provided important mechanistic leads for the preventive efficacy of several classes of synthetic pharmacological agents, including non-streroidal anti-inflammatory drugs (NSAIDs), selective enzyme inhibitors, growth factor receptor antagonists and small molecule inhibitors $(29,32,42$ 49). These observations have demonstrated a direct correlation between the modulation of pathogenesis and the relevant molecular target for efficacy.

Natural phytochemicals. In addition to synthetic pharmacological agents, several naturally occurring dietary phytochemicals have been noted to inhibit intestinal carcinogenesis in genetic models for FAP syndrome $(44,46-48)$. Natural phytochemicals, partly due to their human dietary consumption, may exhibit a favorable toxicity profile and resultant superior compliance. The preventive efficacy of glucobrassinins present in cruciferous vegetables, polyphenols present in tea and isoflavones present in soy have been evaluated in the preclinical cell culture models for breast carcinogenesis $(20-22,24,25,27)$. The newly developed preclinical cell culture models for FAP and HNPCC syndromes are currently being utilized to evaluate the preventive efficacy of natural dietary phytochemicals, such as curcumin and polyphenolic components of green tea.

Combinatorial chemoprevention. Combination chemotherapy represents a widely acceptable mode of management for clinical colon cancer. In contrast, clinical management of FAP is currently restricted to NSAIDs and Coxibs as single agents (49-53). The enhanced risk of cardiovascular problems associated with Coxibs $(54,57,58)$, however, emphasizes the need to identify non-toxic efficacious combinatorial preventive intervention. Preclinical studies on animal models of FAP syndrome have provided evidence for enhanced efficacy with low-dose combinations of mechanistically distinct pharmacological chemopreventive agents $(42,55)$. The preventive efficacy of natural phytochemicals in combination with pharmacological agents, however, remains to be firmly established. 
A recent study on a colon carcinoma cell line has demonstrated that the naturally occurring polyunsaturated fatty acid, Docosahexaenoic acid, in combination with the selective COX-2 inhibitor, Celecoxib, exhibits higher efficacy compared to two agents used independently (56).

The experiments presented in Figs. 1-4, were designed to obtain 'proof of principle' evidence for the concept of combinatorial prevention in the present cell culture models of FAP and HNPCC syndromes. In the FAP model, low-dose combination of SUL+ DFMO exhibited a 3.4-fold decrease in saturation density and a $34.8 \%$ decrease in AICF relative to that observed by SUL or DFMO used independently as single agents (Fig. 1). A similar experiment in the HNPCC model produced a 2.5 -fold and a $45.9 \%$ decrease in the two end-points (Fig. 2).

Preliminary analysis of cell cycle progression in the FAP model revealed that SUL and DFMO independently, as well as in combination, arrest cells in the $\mathrm{G}_{1}$ phase of the cell cycle. In contrast, in the HNPCC model, SUL accumulates the cells in the $S+G_{2} / M$ phase, DFMO accumulates the cells in the $G_{1}$ phase, and SUL+DFMO produces greater $S+G_{2} / M$ arrest (data not shown).

The data generated from the experiment using the CLX+ 5-FU combination in FAP and HNPCC models are presented in Figs. 3 and 4. In the FAP model, low-dose combination of CLX+5-FU produced a 3.1-fold decrease in saturation density and a $19.6 \%$ decrease in AICF relative to that produced by CLX or 5-FU as single agents (Fig. 3). A similar experiment in the HNPCC model produced a 15.4-fold and a $53.8 \%$ decrease in the two end-points (Fig. 4).

Cell cycle analysis in a preliminary experiment revealed that, in the FAP model, CLX+5-FU induces $\mathrm{G}_{1}$ arrest while, in the HNPCC model, this combination produces a strong cumulative synergistic effect on $\mathrm{S}+\mathrm{G}_{2} / \mathrm{M}$ arrest (data not shown).

Distinct differences in cell cycle progression due to treatment with combinations of agents that differ in their mechanism of action have prompted us to monitor the status of relevant $\mathrm{G}_{1}$ or $\mathrm{G}_{2}$ specific cyclins and their respective downstream signaling molecules. These data are likely to identify the molecular targets responsible for enhanced efficacy of the combinations that exhibit additive/synergistic interactions $(32,35,42,55,56,59)$.

\section{Conclusions and future perspectives}

Mouse models for colon cancer with a genetic predisposition to early-onset familial/hereditary carcinogenesis represent valuable preclinical approaches to carcinogenesis and cancer prevention. However, because of the prevalence of small intestinal carcinogenesis in these models, a strong, direct clinical relevance to colon cancer is dependent on extrapolation.

Development and validation of reliable cell culture models with the relevant genetic defect in an appropriate target organ may reduce the need for extrapolation.

The data generated from the recent experiments discussed in this review provide strong phenomenological evidence that preclinical cell culture models for FAP and HNPCC syndromes have an enhanced risk of spontaneous carcinogenic transformation, and that this risk is modifiable by low-dose combinations of mechanistically distinct chemopreventive agents.

The future research directions are focused on elucidating molecular mechanisms responsible for enhanced carcinogenic risk and identifying molecular targets critical for the efficacy of the combinatorial approach. These research directions are expected to validate a mechanism-based rapid screen for a rational prioritization of novel chemopreventive agents for future in vivo animal experiments and subsequent clinical trials.

\section{Acknowledgements}

The research program of the carcinogenesis and chemoprevention laboratory has been funded in part by NCI contract no. NO1-CN-75029-63 and The Irving Weinstein Foundation. Meena Katdare has been supported by CNRU New Investigator Award through NIH Program Project Grant no. P30 CA 29502, and The Irving Weinstein Foundation. The authors wish to acknowledge the participation of Dr Hiroto Ishizuka, in various aspects of the research program, and the expert technical assistance of Milan Zvanovec and Tonye Briggs.

\section{References}

1. Jemal A, Tiwari RC, Murray T, et al: Cancer Statistics, 2005. Cancer J Clin 55: 1-10, 2005.

2. Fodde R, Smits R and Cleavers H: APC signal transduction and genetic instability in colorectal cancer. Nat Rev Cancer 1: 55-67, 2001.

3. Fearon ER and Vogelstein B: A genetic model for colorectal tumorigenesis. Cell 61: 759-767, 1990.

4. Lynch $\mathrm{H}$ and De la Chapelle A: Hereditary colorectal cancer. N Engl J Med 348: 919-932, 2003.

5. Jacks T: Tumor suppressor gene mutations in mice. Annu Rev Genet 30: 603-636, 1996

6. O'Shauhnessy JA, Kelloff GJ, Gordon GB, et al: Treatment and prevention of intraepithelial neoplasia: an important target for accelerated new agent development. Clin Cancer Res 8: 314-346, 2002.

7. Hong WK and Sporn MB: Recent advances in chemoprevention of cancer. Science 278: 1073-1077, 1997.

8. Fodde R, Edelmann W, Yang K, et al: A targeted chain termination mutation in the mouse APC gene results in multiple intestinal tumors. Proc Natl Acad Sci USA 91: 8969-8973, 1994.

9. Moser AR, Pitot HC and Dove WF: A dominant mutation that predisposes to multiple intestinal neoplasia in the mouse. Science 247: 322-324, 1990.

10. Su L-K, Kinzler KW, Vogelstein B, et al: Multiple intestinal neoplasia caused by a mutation in the murine homologue of the APC gene. Science 256: 668-670, 1992.

11. Edelmann W, Yang K, Kuraguchi M, et al: Tumorigenesis in $\mathrm{Mlh}_{1}$ and $\mathrm{Mlh}_{1} / 1638 \mathrm{~N}$ mice. Cancer Res 59: 1301-1307, 1999.

12. Lefebvre AM, Chen IH, Desrelmaux P, et al: Activation of peroxisome proliferator-activated receptor promotes the development of colon tumors in C57BL/6J-Apc $\mathrm{Min} /+$ mice. Nat Med 4: 1053-1057, 1998.

13. Wang D, Wang $\mathrm{H}$, Shi Q, et al: Prostaglandin $\mathrm{E}_{2}$ promotes colorectal adenoma growth via transactiviation of the nuclear peroxisome proliferator-activated receptor- $\delta$. Cancer Cell 6: 285-295, 2004.

14. Paulson JE, Steffensen J-L, Loberg EM, et al: Qualitative and quantitative relationship between dysplastic aberrant crypt foci and tumorigenesis in the Min/+ mouse colon. Cancer Res 61: 5010-5015, 2001.

15. Saez E, Tontonoz P, Nelson MC, et al: Activators of the nuclear receptor PPAR-gamma enhance colon polyp formation. Nat Med 4: 1058-1061, 1998.

16. Zhu Y, Richardson JA, Parada LF, et al: Smad-3 mutant mice develop metastatic colorectal cancer. Cell 94: 703-714, 1998. 
17. Telang NT, Osborne MP, Sweterlilsch LA, et al: Neoplastic transformation of mouse mammary epithelial cells by deregulated myc expression. Cell Regulation 1: 863-872, 1990.

18. Telang NT, Narayanan R, Bradlow HL, et al: Coordinated expression of intermediate biomarkers for tumorigenic transformation in Ras-transfected mouse mammary epithelial cells. Breast Cancer Res Treat 18: 155-163, 1991.

19. Subbaramaiah K, Telang N, Ramonetti JT, et al: Transcription of Cyclooxygenase- 2 is enhanced in transformed mammary epithelial cells. Cancer Res 56: 4424-4429, 1996.

20. Telang NT: Oncogenes, estradiol metabolism, and mammary carcinogenesis. Ann NY Acad Sci 784: 277-287, 1996.

21. Telang NT, Katdare M, Bradlow HL, et al: Inhibition of proliferation and modulation of estradiol metabolism: novel mechanisms for breast cancer prevention by the phytochemical indole-3-carbinol. Proc Soc Exp Biol Med 216: 246-252, 1997.

22. Katdare M, Osborne MP and Telang NT: Inhibition of proliferation and induction of apoptosis in preneoplastic human mammary epithelial cells by natural phytochemicals. Oncol Rep 5: 311-315, 1998 .

23. Sharma HW, Sokoloski JA, Perez JR, et al: Differentiation of immortal cells inhibits telomerase activity: Proc Natl Acad Sci USA 92: 12343-12346, 1995.

24. Katdare M, Osborne MP and Telang NT: Soy isoflavone genestein modulates cell cycle progression and induces apoptosis in HER-2/ neu oncogene expressing human breast epithelial cells. Int $\mathbf{J}$ Oncol 21: 809-815, 2002.

25. Katdare M, Osborne MP and Telang NT: Novel cell culture models for prevention of human breast cancer (review). Int $\mathrm{J}$ Oncol 22: 509-515, 2003.

26. Jinno H, Steiner MG, Mehta RG, et al: Inhibition of aberrant proliferation and induction of apoptosis in HER-2/neu oncogene transformed human mammary epithelial cells by $\mathrm{N}$-(4-hydroxyphenyl) retinamide. Carcinogenesis 20: 229-236, 1999.

27. Subbaramaiah K, Chung WJ, Michaluart $\mathrm{P}$, et al: Resveratrol inhibits cyclooxygenase- 2 transcription and activity in phorbol ester treated human mammary epithelial cells. J Biol Chem 273: 21875-21882, 1998 .

28. Jinno H, Steiner MG, Mason-Burchenal K, et al: Preventive efficacy of receptor class selective retinoids on HER-2/neu oncogene expressing preneoplastic human mammary epithelial cells. Int J Oncol 21: 127-134, 2002.

29. Giardiello FM, Hamilton SR, Hylind LM, et al: Ornithine decarboxylase and polyamines in familial adenomatous polyposis. Cancer Res 57: 199-201, 1997.

30. Katdare M, Kopelovich L and Telang NT: Chemopreventive agents inhibit aberrant proliferation of the aneuploid phenotype in a colon epithelial cell line established from APC 1638N [+/-] mouse. Ann NY Acad Sci 952: 169-174, 2001.

31. Katdare M, Kopelovich L and Telang NT: Efficacy of chemopreventive agents on growth inhibition APC [+/-] 1638NCOL colonic epithelial cells. Int J Mol Med 10: 427-432, 2002.

32. Gerner EW and Meyskens FL: Polyamines and cancer: old molecules, new understanding. Nat Rev Cancer 4: 785-792, 2004.

33. Telang $\mathrm{N}$ and Katdare $\mathrm{M}$ : Prevention of familial colon cancer: novel cell cluture models and mechanistic biomarkers. Int J Mol Med 10: S28, 2002.

34. Telang N and Katdare M: Preventive modulation of colon carcinogenesis: a cell culture approach. Int J Mol Med 12: S19, 2003.

35. Telang $\mathrm{N}$ and Katdare $\mathrm{M}$ : Combinatorial chemoprevention of the high risk familial adenomatous polyposis (FAP) colon cancer syndrome. Int J Mol Med 13: S-45, 2004.

36. Telang $\mathrm{N}$ and Katdare M: Combinatorial chemoprevention of hereditary non-polyposis colon cancer: models and biomarkers. Ind J Med Res 121: 48-49, 2005.

37. Fodde R, Kuipers J, Rosenberg C, et al: Mutations in the APC tumor suppressor gene cause chromosomal instability. Nat Cell Biol 3: 433-438, 2001

38. Kaplan KB, Burds AA, Swedlow JR, et al: A role for the adenomatous polyposis coli protein in chromosome segregation. Nat Cell Biol 3: 429-432, 2001.
39. Chen L-G, Hao C-Y, Chiu YSY, et al: Alteration of gene expression in normal appearing colon mucosa of $\mathrm{Apc}^{\mathrm{Min}}$ mice and human cancer patients. Cancer Res 64: 3694-3700, 2004.

40. Martin AM and Weber B: Genetic and hormonal risk factors in breast cancer. J Natl Cancer Inst 92: 1126-1135, 2000.

41. Fabian CJ, Kimler BF, Elledge RM, et al: Models for early chemoprevention trials in breast cancer. Hematol Oncol Clin North Am 12: 993-1017, 1998.

42. Jacoby RF, Cole CE, Tutsch K, et al: Chemopreventive efficacy of combined Piroxicam and Difluoromethyl ornithine treatment on APC mutant MIN mouse adenoma, and selective toxicity against APC mutant embryos. Cancer Res 60: 1864-1870, 2000 .

43. Jacoby RF, Siebert K, Cole CE, et al: The cyclooxygenase inhibitor Celecoxib is a potent preventive and therapeutic agent in the Min mouse model of adenomatous polyposis. Cancer Res 60: 5040-5044, 2000

44. Corbet DE and Pierre F: Point: from animal models to prevention of colon cancer. Systematic review of chemoprevention in Min mice and choice of the model system. Cancer Epidemiol Biomarkers Prev 12: 391-400, 2003.

45. Oshima M, Murai (Hata) N, Kargman S, et al: Chemoprevention of intestinal polyposis in the Apc ${ }^{716}$ mouse by Refecoxib, a specific cyclooxygenase-2 inhibitor. Cancer Res 61: 1733-1740, 2001.

46. Oshima M, Takahashi M, Oshima $\mathrm{H}$, et al: Effects of Docosahexaenoic acid (DHA) on intestinal polyp development in $\mathrm{Apc}^{716}$ knockout mice. Carcinogenesis 16: 2605-2607, 1995.

47. Paulson JE, Elvaas I, Steffensen KO, et al: Fish oil derived concentrate enriched in eicosapentaenoic acid and docosahexaenoic acid ethyl esters suppress the formation and growth of intestinal polyps in the Min mouse. Carcinogenesis 18: 1905-1910, 1997.

48. Perkins S, Verschoyle RD, Hill K, et al: Chemopreventive efficacy and pharmacokinetics of Curcumin in the Min/+ mouse, a model for familial adenomatous polyposis. Cancer Epidemiol Biomarkers Prev 11: 535-540, 2002.

49. Abbruzzese JL and Lippman SM: The convergence of cancer prevention and therapy in early-phase clinical drug development. Cancer Cell 6: 321-326, 2004.

50. Baron JA, Cole BF, Sandler RS, et al: A randomized trial of aspirin to prevent colorectal adenomas. N Engl J Med 348: 891-899, 2003.

51. Giardiello FM, Hamilton SR, Krush AH, et al: Treatment of colonic and rectal adenomas with sulindac in familial adenomatous polyposis. N Engl J Med 328: 1313-1316, 1993.

52. Steinbach G, Lynch PM, Phillips RKS, et al: The effect of Celecoxib, a cyclooxygenase inhibitor in familial adenomatous polyposis. N Engl J Med 342: 1946-1952, 2000.

53. Gupta RA and Dubois RN: Colorectal cancer prevention and treatment by inhibition of cyclooxygenase-2. Nat Rev Cancer 1: $11-21,2001$

54. Couzin J: Nail-biting time for trails of Cox-2 drugs. Science 306: 1673-1675, 2004

55. Torrance CJ, Jackson PE, Montgomery E, et al: Combinatorial chemoprevention of intestinal neoplasia. Nat Med 6: 1024-1028, 2000.

56. Swamy MV, Cooma I, Jagan MR, et al: Modulation of cyclooxygenase- 2 activity by the combined action of Celecoxib and docosahexaenoic acid: novel strategies for prevention and treatment. Mol Cancer Ther 3: 215-223, 2004

57. Solomon SD, McMurray JJV, Pfeffer MA, et al: Cardiovascular risk associated with Celecoxib in a clinical trial for colorectal adenoma prevention. N Engl J Med 352: 1071-1080, 2005.

58. Bresalier RS, Sandler RS, Quan H, et al: Cardiovascular events associated with Rofecoxib in a colorectal adenoma chemoprevention trial. N Engl J Med 352: 1092-1102, 2005.

59. Telang N, Li G and Katdare M: Prevention of early onset colon cancer. Int J Mol Med 16: S-35, 2005. 